\title{
Experimental study of friction dissipators for seismic protection of building structures
}

\author{
F. López-Almansa ${ }^{1}$, S.T. de la Cruz ${ }^{2}$ and C. Taylor ${ }^{3}$ \\ ${ }^{1}$ Professor, Technical University of Catalonia, Architecture Structures Department, Barcelona, Spain \\ ${ }^{2}$ Associate Professor, Universidad Autónoma de Ciudad Juárez, Civil and Environmental Engineering \\ Department, Ciudad Juárez, Chihuahua, Mexico \\ ${ }^{3}$ Professor, University of Bristol, Civil Engineering Department, Bristol, UK
}

\begin{abstract}
This paper presents unidirectional shaking table tests of two reduced scale steel models of building frames; they have one and two floors, respectively. Such frames incorporate friction dissipators at every floor. The inputs are sine-dwells and artificial and registered earthquakes. This work belongs to a larger research project aiming to assess the seismic efficiency of friction dissipators by means of an integrated numerical and experimental approach. Inside this framework, the main objectives of these experiments are: (i) to collect a wide range of results useful to calibrate a numerical model derived inside the project, (ii) to contribute to clarify some of the most controversial issues about friction dissipators (behavior for inputs containing pulses, capacity to cut resonance peaks, introduction of high frequencies in the response, self-generated eccentricities), (iii) to better understand their dynamic behavior, (iv) to give an insight on the feasibility and reliability of using simple friction dissipators for seismic protection of building structures and (v) to characterize the hysteretic behavior of these devices. Most of these objectives are satisfactorily reached and relevant conclusions are stated.
\end{abstract}

Keywords: Building Structures; Earthquake Engineering; Passive Control; Friction Energy Dissipators; Experimental Verification; Shaking Table Tests.

Acknowledgements: This work is a part of the ECOLEADER Project, funded by the European Commission through its Framework 5: Access to Large Infrastructures Program; this support is gratefully acknowledged. This paper has been also supported by the Spanish Government, grant CGL2008-00869/BTE.

Correspondence to: Francisco López-Almansa; Departament d'Estructures; ETSAB (UPC); Avda. Diagonal 649; 08028 Barcelona (Spain); Phone +34934016316, FAX +34934016096; E-mail:

francesc.lopez-almansa@upc.edu 


\section{Introduction}

In earthquake engineering, the traditional design approach consists of designing ductile constructions and thus dissipating the input energy through large strains in the main structure. However, these strains imply damage. Conversely, the use of energy dissipation devices not belonging to the main gravity loadresisting system was suggested in the 1970s (Hanson et al. 1997, Housner et al. 1997, Soong and Dargush 1997). These devices are specifically designed to absorb the input energy, thus protecting the main structure. Moreover, they can be easily replaced after strong excitations. Fig. 1 shows three sketches of moment resisting frames equipped with energy dissipators.

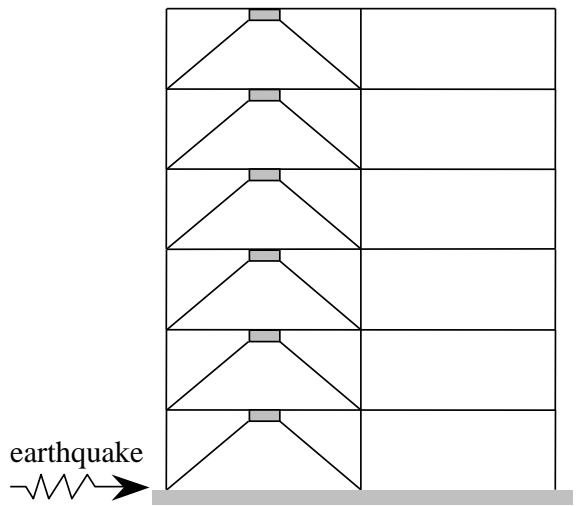

(a)

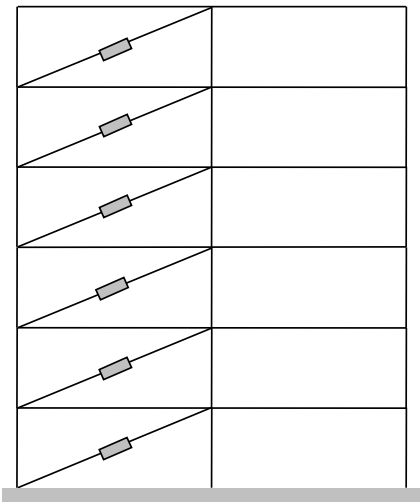

(b)

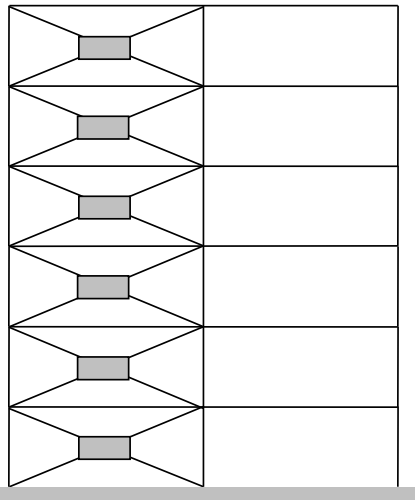

(c)

Fig. 1. Building frames equipped with energy dissipators

The systems depicted in Fig. 1 are intended to reduce the inter-story drifts. In Fig. 1a dissipators are placed between the main structure and the bracing system, Fig. 1b displays sliding dissipators connected to two split diagonal braces while Fig. 1c shows devices connected to four half-braces. In all these cases the inter-story drift motion generates strains in the devices, thus producing energy dissipation.

Three major types of energy dissipators are used: (a) devices with viscous or viscoelastic materials, (b) devices based on plastification of metals and (c) friction devices. For each of these types, Fig. 2 shows typical hysteresis loops; the interaction forces $F$ are plotted vs. the relative displacements $d$.

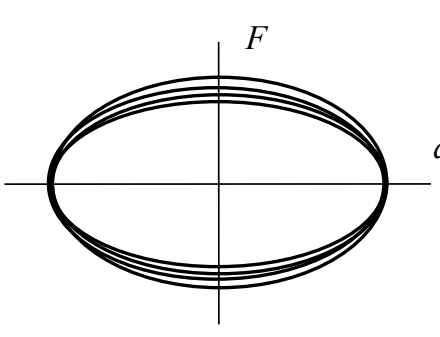

(a) Viscous or viscoelastic

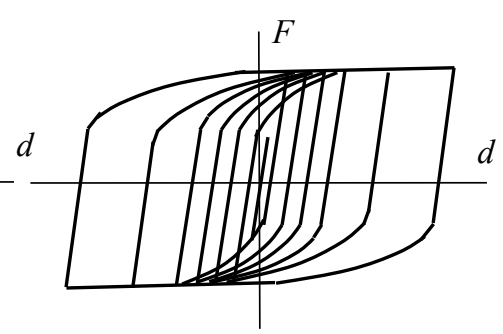

(b) Metal

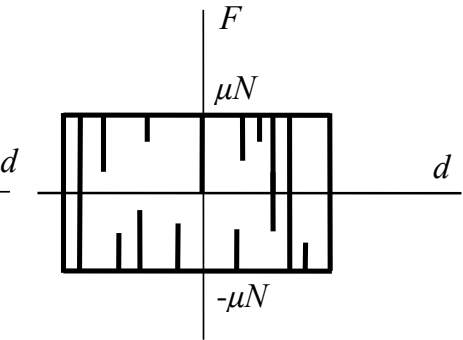

(c) Friction

Fig. 2. Hysteresis loops of energy dissipators

Fig. 2a shows that the behavior of viscous or viscoelastic dissipators is rather linear as their hysteresis loops are near elliptic (Chopra 2001). Conversely, the behavior of metal (Fig. 2b) and friction devices (Fig. 2c) is non-linear. Fig. 2c shows typical loops of a friction device; these plots are based on a simple Coulomb model and indicate that the friction force cannot exceed the sliding thresholds $\pm \mu N$, where $\mu$ 
is the friction coefficient and $N$ is the transversal prestressing force. Since the friction force always opposes motion, every time it reverses there is an abrupt vertical discontinuity between $\mu N$ and $-\mu N$; consequently, the behavior is highly nonlinear.

This paper focuses on friction dissipators. Such devices have several relevant advantages:

- High energy dissipation per cycle at a given amplitude, since the hysteresis loops are rectangular as shown in Fig. 2c.

- Virtually boundless dissipation capacity, mainly limited by the wearing of the sliding surface.

- Controllable sliding thresholds through transversal prestressing forces.

A variety of friction dissipators have been proposed for structural energy dissipation (Pall and Marsh 1982, Palsson et al. 1984, Tyler 1985, Sumitomo 1987, Pall 1989, Richter et al. 1990, Vezina et al. 1992, Cherry and Filiatrault 1993, Nims et al. 1993, Grigorian et al. 1993, Way 1996, Soong and Dargush 1997, Housner et al. 1997, Wu and Ou 2003, Cho and Kwon 2004, Morgen and Kurama 2004, Tsai et al. 2008, Morgen and Kurama 2008), design criteria have been issued (Rao et al. 1996, Colajanni and Papia 2008, Levy et al. 2000, Moreschi and Singh 2003, De la Llera et al. 2005, Levy, Lavan and Rutenberg 2005), numerical simulation algorithms have been formulated (Dimova et al. 1995, De la Cruz et al. 2007, Lu et al. 2006) and a number of applications have been reported (Pall et al. 1993, Tena 2007, Zhou et al. 2007). In the reference (Dimova and Hirata 2000) a study about the seismic efficiency of friction dissipators is presented. The proposed devices differ in their mechanical complexity and in the materials used in the sliding surfaces, but if it is assumed that the friction coefficient is non-velocitydependent, that the static and dynamic friction coefficients are equal and that the prestressing force is constant, almost all of them generate near-rectangular hysteresis loops as the one depicted in Fig. 2c. Only the so-called EDR (Energy Dissipating Restraint) devices (Richter et al. 1990; Nims et al. 1993) exhibit significantly different loops since their mechanism is not purely frictional but is combined with spring elements; depending on the spring constant, the initial slip load, and other parameters, several different types of hysteretic behavior are possible.

In spite of the relevant existing background about friction dissipators there are still some open questions that can jeopardize their seismic efficiency:

- The energy dissipated per cycle is proportional to the maximum displacement (see Fig. 2c) instead of being proportional to its square, as in viscous or viscoelastic dampers (see Fig. 2a). This fact can be relevant for inputs containing either sudden pulses or unexpectedly high amplitudes, since in both cases large displacements can arise. Moreover, resonance peaks cannot be properly cut as discussed by Den Hartog (1985); that author showed that if a friction device is driven by a harmonic input whose force amplitude is $f_{0}$, the amplitude at resonance is infinite unless $\mu N>f_{0} \pi / 4$.

- Due to the frequent and sudden changes in the sticking-sliding conditions and to the abruptness of the relative motion switching (see Fig. 2c), high frequencies might be introduced in the response (Housner et al. 1997), mainly in the acceleration. This might be relevant both for human comfort conditions and for damage in non-structural elements.

- Given the inherent uncertainty of the values of the sliding thresholds $\pm \mu N$, some twist effects might arise, even in symmetrical buildings (De la Llera et al. 2005).

- Durability is open to discussion, mostly due to the high sensitivity of the friction coefficient to the conditions in the sliding surfaces.

To shed light on these issues is not easy, either by testing or by numerical simulation:

- $\quad$ Reported experiments (Tyler 1985, Filiatrault and Cherry 1987, Fitzgerald et al. 1989, Anagnostides and Hargreaves 1990, Aiken and Kelly 1990, Richter et al. 1990, Whittaker et al. 1991, Aiken et al. 1993, Grigorian et al. 1993, Yang and Popov 1995, Wu and Ou 2003, Morgen and Kurama 2004, Ng and Xu 2006, Vial et al. 2005, Ricles et al. 2006, Zhu et al. 2006, Tsai et al. 2008, Morgen and 
Kurama 2008, Iyama et al. 2009) do not yield enough information about those questions, as they are mostly oriented to check the global validity of particular devices or assemblies.

- The numerical simulation constitutes a challenging issue as the dynamic behavior of friction devices is highly nonlinear, as discussed previously. Moreover, the proper simulation of the high frequency motion can be particularly difficult. The existing models are either computationally costly (based on Lagrange multipliers or penalty methods, Bathe 1982) or rather inaccurate (based on bilinear or elasto-plastic simple models, Foti et al. 1998).

This work belongs to a larger research project aiming to clarify these issues using an integrated numerical and experimental approach. The final objective is to investigate the efficiency of friction dissipators for seismic protection of buildings (De la Cruz et al. 2002, De la Cruz 2003). The project consists of the following stages: (i) developing a new numerical model of the dynamic behavior of buildings equipped with friction dissipators (De la Cruz et al. 2001, De la Cruz et al. 2007), (ii) testing laboratory models of building structures incorporating friction dissipators, (iii) calibrating the proposed numerical model with these experimental results and with other ones available in the technical literature, and (iv) performing a numerical parametric assessment of the seismic efficiency of friction dissipators using the proposed model. The first three stages are already completed while the fourth one is in progress. This paper focuses on the experiments, i.e., the second stage. It should be noted that this research is not restricted to any particular device, but rather to all the dissipators whose hysteretic behavior can be roughly described by Fig. 2c.

Inside the framework of the aforementioned research project, these tests pursue the following objectives:

- To collect a wide set of experimental results useful to calibrate the proposed numerical model.

- To contribute to clarify some of the aforementioned four controversial issues, namely, behavior for inputs containing pulses, capacity to cut resonance peaks, introduction of high frequencies in the response, and self-generation of twisting motion.

- To better understand the dynamic behavior of friction dissipators.

- To give an insight on the feasibility of using simple, yet robust and reliable friction dissipators.

- To characterize the hysteretic behavior of these devices, as to allow their implementation in designoriented computers codes.

The experiments are designed to reach these goals, yet accounting for the time, availability and budget constraints.

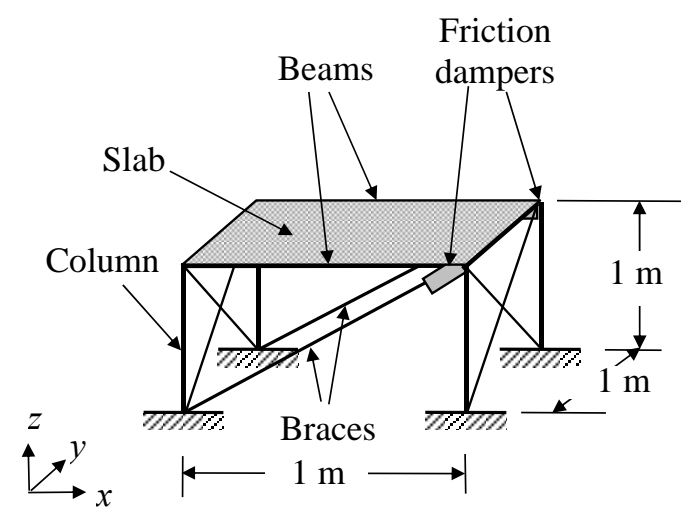

(a) Single-story model

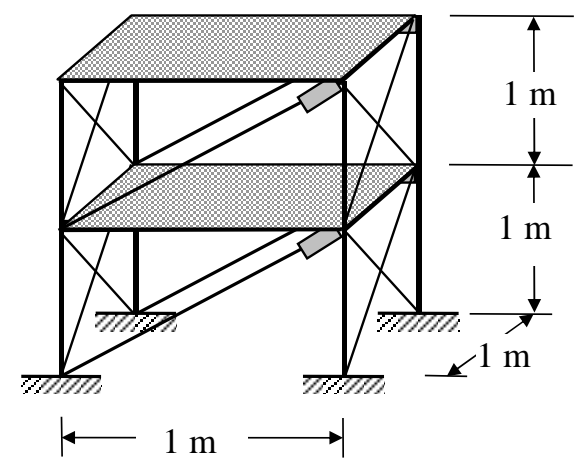

(b) Two-story model

Fig. 3. Tested models 


\section{Tests description}

\subsection{General remarks}

The experiments consist of unidirectional shaking table tests of two steel frames, designed as reduced scale models of building structures with one and two floors, respectively. Such frames incorporate a pair of parallel friction dissipators in each level. A deeper description of the tests can be found in the reference De la Cruz (2003). The experiments were carried out in the BLADE laboratories of the University of Bristol (UK).

\subsection{Testing frames}

Fig. 3 sketches the two tested frames, while Fig. 4 displays a picture of the single-story frame.

Fig. 3 and Fig. 4 show that the steel frames have plan symmetry and are rigidly braced in the $y$ direction as only the motion in the orthogonal direction $(x)$ is of interest. The braces in $x$ direction are interrupted by the friction dissipators similarly to Fig. 1b. The main frame members (beams and columns) have square hollow sections (SHS), the transversal braces ( $y$ direction) are thin stripes and the longitudinal braces ( $x$ direction) have circular hollow sections (CHS). The beams and columns are rigidly connected to each other; the joints between braces and frames are hinged lubricated bolted connections. The member sections for both models are shown in Table 1. Such geometrical parameters as well as the added masses are mainly selected to provide natural periods similar to those of real buildings with the same number of stories. All the members are made with structural steel, grade 43 . Both models are rigidly fixed to the shaking table.

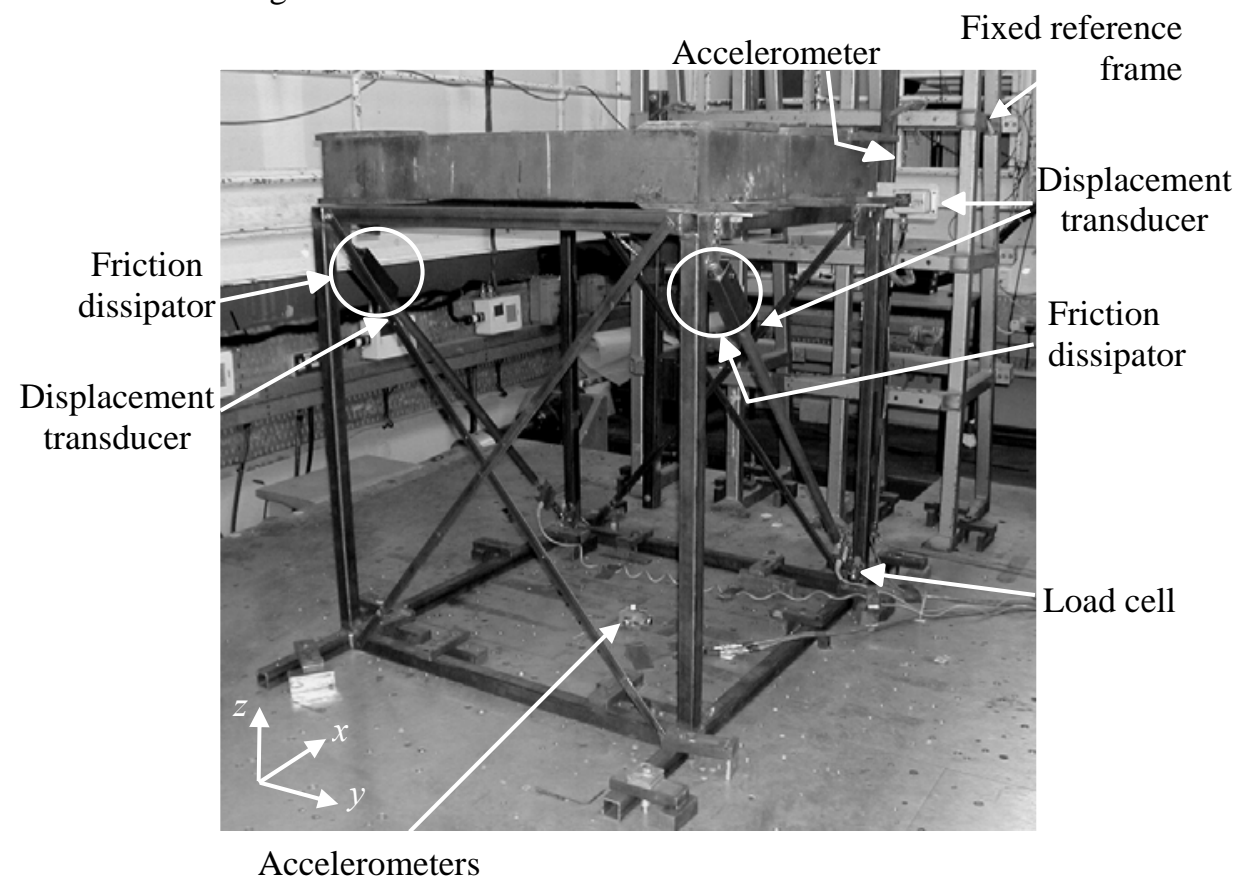

Fig. 4. Single-story model

The tested frames can work, along $x$ axis, under three different conditions: (i) without braces, (ii) with all 
the friction dissipators blocked (i.e., any sliding is prevented) and (iii) with normal operation of the dissipators (i.e., sliding is not prevented). Such conditions are termed next as bare frame, braced frame and protected frame, respectively. These conditions correspond to feasible situations of real buildings; hence, proper efficiency of the dissipators requires that the protected frame performs better than both the bare and the braced one. Only the protected frames were tested. The responses of the bare and braced frames were computed for comparison purposes; linear behavior was assumed.

Table 1. Member sections of both models

\begin{tabular}{cc}
\hline Member & Section $(\mathrm{mm})$ \\
\hline Column & SHS $40 \times 40 \times 3$ \\
Beam & SHS $40 \times 40 \times 3$ \\
Brace $(x z)$ & CHS $26.9 \times 3.2$ \\
Brace $(y z)$ & Stripe $25 \times 3$
\end{tabular}

The frames behave linearly since the nonlinearities are concentrated in the dissipators; consequently, their behaviors are only characterized by the mass, stiffness and damping coefficients. Since the two structures are symmetric, their horizontal vibrations are described by discrete lumped masses models with one degree-of-freedom (DOF) per floor ( $x$ displacement). In the protected frames, the relative motion of the dissipators with respect to the frames is described by additional DOFs (see Section 3). The values of the structural parameters are listed next.

For both frames the mass of the first floor is $1067 \mathrm{~kg}$, for the two-storey model the mass of the second floor is $1105 \mathrm{~kg}$. For the numerical simulations the halves of these values are used, given that single frames (i.e. front or rear) are considered; hence, for the single-story model the mass coefficient is $m=533.5 \mathrm{~kg}$ while for the two-storey model the mass matrix is $\mathbf{M}=\operatorname{diag}(533.5,552.5) \mathrm{kg}$. The mass of the bracing system is neglected; this assumption is supported by comparison between numerical and experimental results.

The natural periods are determined experimentally from white noise tests (De la Cruz 2003). For the single-story model the obtained average values are $T_{1}=0.2418 \mathrm{~s}$ for the bare frame and $T_{1}=0.0879 \mathrm{~s}$ for the braced frame. For the two-storey frame the two average periods of the first two eigenmodes are $T_{1}=0.4696 \mathrm{~s}$ and $T_{2}=0.1563 \mathrm{~s}$ for the bare frame and $T_{1}=0.1992 \mathrm{~s}$ and $T_{2}=0.0751 \mathrm{~s}$ for the braced frame. The comparison between the values for the bare and braced frames shows the large stiffening effect generated by the diagonal braces.

The stiffness coefficients of the bare frame are determined by theoretical considerations validated by static lateral loading tests. For the single-story model the stiffness coefficient is $k=334.597 \mathrm{kN} / \mathrm{m}$; for the two-storey model the stiffness matrix is $\mathbf{K}=\left(\begin{array}{cc}808.375 & -351.467 \\ -351.467 & 267.115\end{array}\right) \mathrm{kN} / \mathrm{m}$. The stiffness coefficients of the bracing systems are obtained by deducting those of the bare frames from those of the braced ones. These last values are not obtained from theoretical considerations due to the difficulties in evaluating the axial stiffness of the braces since load-cells are connected to them, thus they behave as non-constant section members (see Fig. 4); hence, the stiffness coefficients of the bracing are determined (De la Cruz 2003) from the measured natural periods of the braced frames and their masses (Chopra 2001). For the single-story model such coefficient is $k^{\prime}=2390.57 \mathrm{kN} / \mathrm{m}$; for the two-storey model the stiffness matrix of the bracing is $\mathbf{K}^{\prime}=\left(\begin{array}{cc}2262.78 & -968.89 \\ -968.89 & 968.89\end{array}\right) \mathrm{kN} / \mathrm{m}$. The comparison among coefficients $k^{\prime}$ and $k$ and among matrices $\mathbf{K}^{\prime}$ and $\mathbf{K}$ shows that, in the horizontal $x$ direction, the diagonal braces are significantly stiffer than the frames.

The viscous damping coefficients of the bare frame are determined (De la Cruz 2003) from the above mentioned natural periods and from the identified modal damping ratios (Chopra 2001); for the two- 
storey model the damping matrix in modal coordinates is assumed to be diagonal. Such damping factors are obtained from white noise tests as the ratio between the real and imaginary parts of the poles of the transmissibility function between the shaking table input motion and the frame acceleration response. For the single-story model the damping ratio is $\xi_{1}=0.003141$ while for the two-storey one the modal damping ratios are $\xi_{1}=0.004608$ and $\xi_{2}=0.001636$ for the first and the second vibration modes, respectively. Since no damage is expected in the main structure, such values can be used for numerical simulation in spite that the motion amplitudes in the main tests will be significantly higher than those in the white noise case. For the single-story model the damping coefficient is $c=83.932 \mathrm{Ns} / \mathrm{m}$; for the twostorey model the damping matrix is $\mathbf{C}=\left(\begin{array}{cc}72.692 & -4.065 \\ -4.065 & 68.688\end{array}\right) \mathrm{Ns} / \mathrm{m}$. The damping of the bracing systems is neglected.

\subsection{Friction dissipators}

All the dissipators are alike. They consist of a hollow long prismatic block of stainless steel with a cut (slot) along its length. The hole is shaped as a cylinder whose axis goes along the length of the block to hold the circular brace (see Fig. 4). Fig. 5a shows a lone device, Fig. 5b displays a dissipator mounted in a brace, and Fig. 5c and Fig. 5d show a longitudinal cut and a cross section, respectively. As shown in Fig. 5, two transversal smaller holes were drilled in the block to hold two adjustable bolts to control the prestressing normal force between the dissipator and the brace. The migration of the device along the brace is prevented by connecting rigidly its upper end and allowing only sliding of the lower one (Fig. 5b). The sliding surfaces of the dissipator and the brace were thoroughly smoothed.

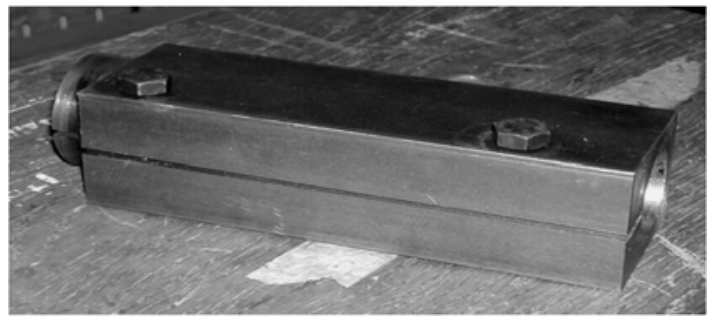

(a)

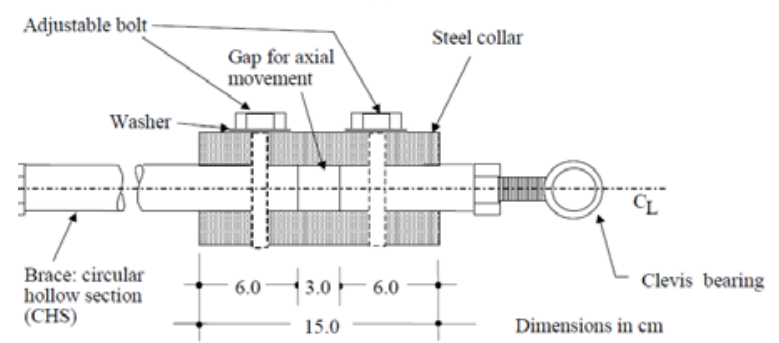

(c)

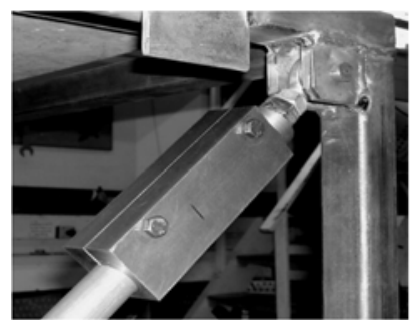

(b)

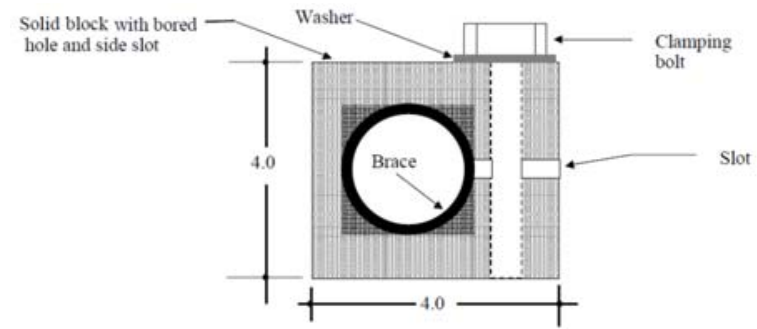

(d)

Fig. 5. Friction dissipator

The relationship between the applied torque and the sliding threshold ( $\mu N$, see Fig. $2 c)$ is experimentally determined (De la Cruz 2003); the behaviors under compression and tension loads are not identical, as confirmed by the main tests (see Table 2 and Table 3). The clamping forces of the bolts were chosen aiming to generate sliding of the friction devices under the selected inputs (De la Cruz 2003). These values are mainly used for preliminary design purposes; for the numerical simulations, the sliding thresholds are instead identified from the main measured results. 


\subsection{Input signals}

The two rigs shown in Fig. 3 were mounted on a shaking table and underwent several types of unidirectional dynamic excitations: sine dwells and scaled registered and artificial earthquakes. Table 2 and Table 3 show, for each input, the sampling periods of the digital control loops governing the tests, the main features of the input and the values of the positive and negative sliding thresholds $(\mu N)$ of the friction forces which are assumed for the numerical simulations; positive values of $\mu N$ correspond to tensioned braces.

Table 2. Inputs and sliding thresholds $(\mu N)$. Single-story model

\begin{tabular}{ccccccc}
\hline Input & $\begin{array}{c}\text { Sampling } \\
\text { period }(\mathrm{s})\end{array}$ & $\begin{array}{c}\text { Frequency } \\
(\mathrm{Hz})\end{array}$ & $\begin{array}{c}\text { Peak Ground } \\
\text { Acceleration }(\mathrm{g})\end{array}$ & $\begin{array}{c}\text { Total } \\
\text { duration } \\
(\mathrm{s})\end{array}$ & $\begin{array}{c}\text { Positive sliding } \\
\text { threshold } \mu N \\
(\mathrm{~N})\end{array}$ & $\begin{array}{c}\text { Negative sliding } \\
\text { threshold } \mu N \\
(\mathrm{~N})\end{array}$ \\
\hline $\begin{array}{c}\text { Sine dwell } \\
\text { Northridge }\end{array}$ & 0.0025 & 4 & 0.298 & 12.5 & 853.21 & -1127.81 \\
$\begin{array}{c}\text { Earthquake } \\
\text { San Fernando } \\
\text { Earthquake }\end{array}$ & 0.0025 & - & 0.396 & 15.0 & 686.49 & -686.49 \\
& 0.0050 & - & 0.452 & 15.0 & 686.49 & -686.49
\end{tabular}

Table 3. Inputs and sliding thresholds $(\mu N)$. Two-storey model

\begin{tabular}{|c|c|c|c|c|c|c|c|c|}
\hline Input & $\begin{array}{l}\text { Sampling } \\
\text { period (s) }\end{array}$ & $\begin{array}{l}\text { Freq. } \\
(\mathrm{Hz})\end{array}$ & $\begin{array}{c}\text { Peak Ground } \\
\text { Acceleration } \\
\text { (g) }\end{array}$ & $\begin{array}{c}\text { Total } \\
\text { duration } \\
\text { (s) }\end{array}$ & $\begin{array}{l}1^{\text {st }} \text { floor } \\
\text { positive } \\
\text { sliding } \\
\text { threshold } \\
\mu N(\mathrm{~N})\end{array}$ & $\begin{array}{l}1^{\text {st }} \text { floor } \\
\text { negative } \\
\text { sliding } \\
\text { threshold } \\
\mu N(\mathrm{~N})\end{array}$ & $\begin{array}{l}2^{\text {nd }} \text { floor } \\
\text { positive } \\
\text { sliding } \\
\text { threshold } \\
\mu N(\mathrm{~N})\end{array}$ & $\begin{array}{l}2^{\text {nd }} \text { floor } \\
\text { negative } \\
\text { sliding } \\
\text { threshold } \\
\mu N(\mathrm{~N})\end{array}$ \\
\hline Sine dwell 1 & 0.0050 & 4 & 0.265 & 12.5 & 745.33 & -745.33 & 882.63 & -882.63 \\
\hline Sine dwell 2 & 0.0050 & 2 & 0.146 & 22.5 & 693.30 & - 813.98 & 460.93 & -675.07 \\
\hline $\begin{array}{l}\text { Northridge } \\
\text { Earthquake }\end{array}$ & 0.0050 & - & 0.242 & 15.0 & 539.39 & - 539.39 & 735.53 & - 735.53 \\
\hline $\begin{array}{l}\text { San Fernando } \\
\text { Earthquake }\end{array}$ & 0.0050 & - & 0.347 & 15.0 & 470.74 & -470.74 & 882.63 & - 882.63 \\
\hline $\begin{array}{c}\text { Artificial } \\
\text { earthquake }\end{array}$ & 0.00375 & - & 0.159 & 15.0 & 559.00 & -264.79 & 813.98 & -951.28 \\
\hline
\end{tabular}

The sine dwell signals consist of harmonic waves; during the first two seconds the amplitude grows linearly, then keeps constant until the last two seconds when decreases linearly until vanishing. The San Fernando Earthquake corresponds to the Pacoima Dam station (February 9 1971, 196 ${ }^{\circ}$ ). The artificial earthquake is generated to fit the spectrum obtained by Newmark et al. (1973). For the single story model (Table 2), the sine dwell and the Northridge Earthquake are selected to discuss controversial issues about friction dissipators. The frequency of the sine dwell signal is extremely close to the natural frequency of the bare frame $\left(f_{1}=4.14 \mathrm{~Hz}\right)$; hence, while the dissipator keeps sliding the motion is near resonance. The Northridge Earthquake corresponds to the Sylmar County Hospital Station (January 17 1994, 90 ${ }^{\circ}$; this signal was selected because contains pulses (Frau and Saragoni 2005) generated by nearsource effects.

Table 2 and Table 3 show that for some inputs the identified values of the positive and negative sliding thresholds are different; this fact is taken into account in the numerical simulations. Except in one case (first floor of the two-storey building under the artificial earthquake, see Table 3), this difference might be generated by the highest difficulty of pushing the brace inside the dissipator rather than pulling it out. This is also observed in the static calibration tests (De la Cruz 2003).

\subsection{Testing equipment}


The measured variables are: (a) input (table) accelerations and displacements, (b) output (floor) accelerations and displacements, (c) friction forces and (d) sliding displacements in the dissipators. Eleven sensors were used in the single-story frame: 3 accelerometers on the base, 2 accelerometers on the top, 2 long stroke displacement transducers on the top, 2 small displacement transducers on the dissipators and 2 load-cells on the diagonal braces; nineteen sensors were used in the two-storey frame: 3 accelerometers on the base, 2 accelerometers on the first floor and 2 on the top, 2 long stroke displacement transducers on the first floor and 2 on the top, 2 small displacement transducers on the first floor dissipators and 2 on the second floor dissipators, and 2 load-cells on the first floor braces and 2 load-cells on the second floor braces. Fig. 4 shows the sensors of the single-story model.

\section{Numerical model}

The tests are simulated with a numerical algorithm developed by some of the authors (De la Cruz et al. 2001, De la Cruz 2003, De la Cruz et al. 2007). This model is intended to describe the nonlinear dynamic behavior of 2D multi-storey frames incorporating friction dissipators in each floor. The motion is described by the two following matrix differential equations:

$$
\begin{aligned}
& \mathbf{M}^{\text {ss }} \ddot{\mathbf{x}}^{\mathrm{s}}+\mathbf{C}^{\text {ss }} \dot{\mathbf{x}}^{\mathrm{s}}+\mathbf{C}^{\text {sd }} \dot{\mathbf{x}}^{\mathrm{d}}+\mathbf{K}^{\text {ss }} \mathbf{x}^{\mathrm{s}}+\mathbf{K}^{\text {sd }} \mathbf{x}^{\mathbf{d}}=-\mathbf{M}^{\text {ss }} \mathbf{r} \ddot{x}_{g}-\mathbf{F} \\
& \mathbf{M}^{\text {dd }} \ddot{\mathbf{x}}^{\mathbf{d}}+\left(\mathbf{C}^{\text {sd }}\right)^{\mathrm{T}} \dot{\mathbf{x}}^{\text {s }}+\mathbf{C}^{\text {dd }} \dot{\mathbf{x}}^{\mathrm{d}}+\left(\mathbf{K}^{\text {sd }}\right)^{\mathrm{T}} \mathbf{x}^{\mathrm{s}}+\mathbf{K}^{\mathrm{dd}} \mathbf{x}^{\mathbf{d}}=-\mathbf{M}^{\mathrm{dd}} \mathbf{r} \ddot{x}_{g}+\mathbf{F}
\end{aligned}
$$

Super-indexes $s$ and $d$ account for the main structure and for the dissipators, respectively, while subindex $g$ refers to ground. Vectors $\mathbf{x}^{\mathrm{s}}$ and $\mathbf{x}^{\mathrm{d}}$ contain the $N$ horizontal displacements of the floors and of the dissipators, respectively, where $N$ is the number of floors. $\mathbf{M}^{\mathrm{ss}}, \mathbf{M}^{\mathrm{dd}}, \mathbf{C}^{\mathrm{ss}}, \mathbf{C}^{\mathrm{sd}}, \mathbf{C}^{\mathrm{dd}}, \mathbf{K}^{\mathrm{ss}}, \mathbf{K}^{\text {sd }}$ and $\mathbf{K}^{\mathrm{dd}}$ are mass, damping and stiffness matrices, respectively. Vector $\mathbf{F}$ contains the $N$ interaction friction forces and, finally, $\mathbf{r}=(1, \cdots, 1)^{\mathrm{T}}$ is an unit vector.

The numerical solution of equations (1) and (2) is arduous mainly because of three reasons: (a) they are highly nonlinear due to the abrupt shifts in the friction forces every time the sliding motion reverts, (b) they are coupled trough the friction forces $\mathbf{F}$ and the matrices $\mathbf{K}^{\text {sd }}$ and $\mathbf{C}^{\text {sd }}$ and (c) the continuous changes in the sliding or sticking conditions in the dissipators causes that the number of degrees of freedom to be computed changes continuously, ranging in between $N$ and $2 N$, as shown next. When there is sticking in every dissipator the velocities of the floors and of the dissipators are equal $\left(\dot{\mathbf{x}}^{\mathrm{d}}=\dot{\mathbf{x}}^{\mathrm{s}}\right)$ and only $N$ degrees of freedom are needed to describe the motion. Conversely, when some devices slide, the corresponding velocities $\dot{x}_{i}^{d}$ and $\dot{x}_{i}^{s}$ are not related and, hence, the required number of degrees of freedom is higher. If all the devices slide simultaneously, the required number of degrees of freedom is $2 N$. To solve equations (1) and (2), a modification of the linear acceleration method (Chopra 2001) is proposed; three nested iteration loops are used, their completion guarantees the fulfillment of equations of motion (1) and (2) and of the constitutive laws of the dissipators (Fig. 2c).

Results given by this algorithm have been satisfactorily compared (De la Cruz et al. 2001, De la Cruz 2003, De la Cruz et al. 2007) to other numerical results from the ADINA software package (Bathe 1982).

\section{Numerical vs. experimental results}

This section presents numerical and experimental results; three major purposes are pursued: (a) to discuss some issues about the actual behavior of the dissipators, (b) to investigate the influence of irregularly shaped hysteresis loops and (c) to further validate the accuracy and reliability of the proposed model, mainly under modeling uncertainties. All the results discussed in this section correspond to the two-storey model and the artificial earthquake (see Table 3); similar conclusions are derived from the other cases (De la Cruz 2003). 
Fig. 6 displays, for the first floor dissipator, experimental hysteresis loops in terms of the horizontal component of the friction force $F_{1}$ and the relative displacement between the main frame and the brace $\left(x_{1}^{d}-x_{1}^{S}\right)$. In the vertical axis positive values of $F_{1}$ correspond to tension and in the horizontal axis positive values of $x_{1}^{d}-x_{1}^{s}$ correspond to elongation, i.e. the brace going out from the block (see Fig. $5 b)$.

Fig. 6 shows that the actual hysteretic behavior of the dissipators does not fit the Coulomb model depicted by Fig. 2c. Two major irregularities can be observed: (a) the two sliding branches are non flat but the forces are larger for higher penetration length of the brace inside the block and (b) the sliding thresholds at the superior and inferior branches are different. Both circumstances can be observed, more or less clearly, in the other experiments (about the second issue, see Table 2 and Table 3). The first irregularity can be explained by the increase of the sliding length as the brace penetrates inside the block.

800

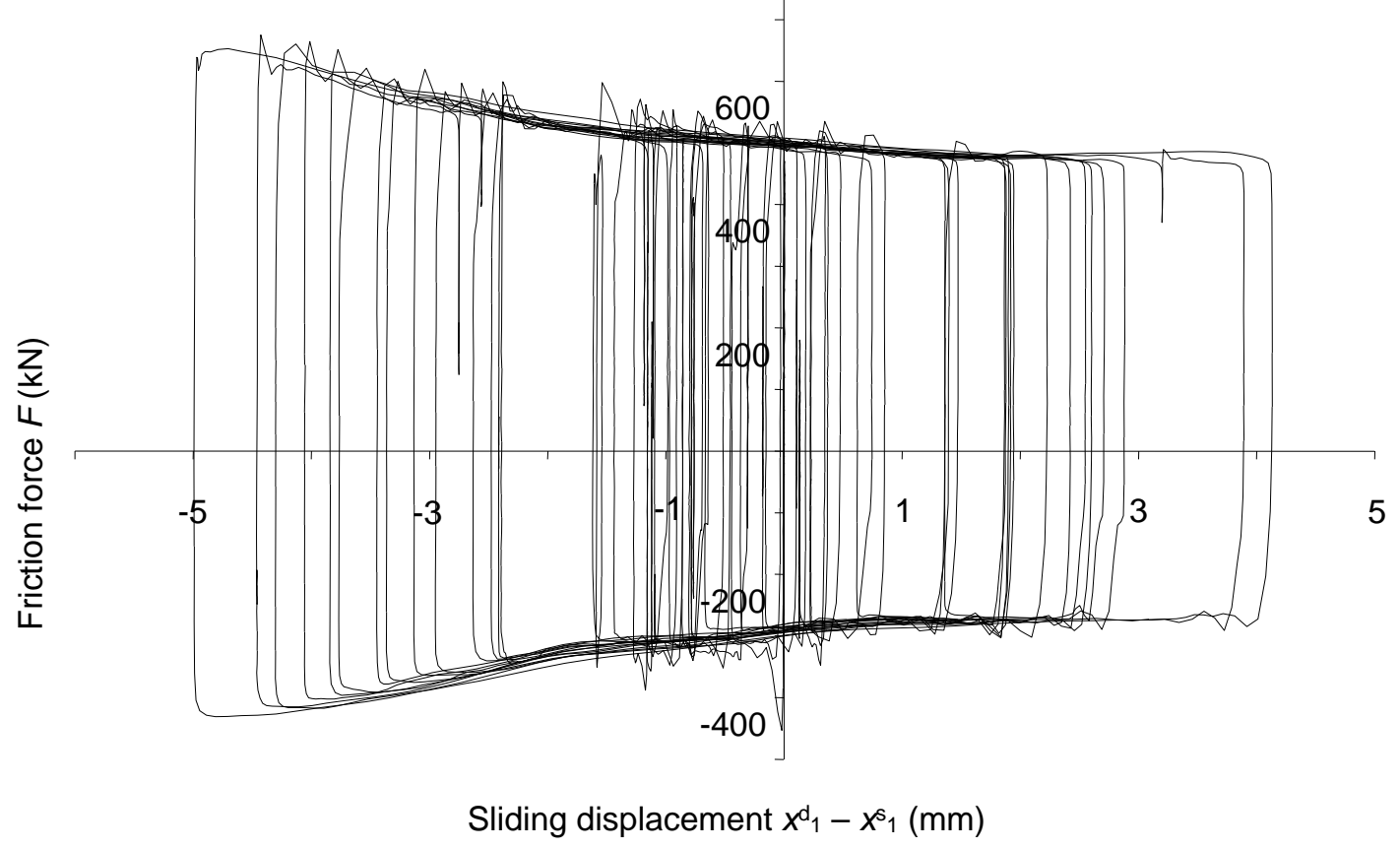

Fig. 6. Experimental hysteresis loops of the first floor dissipator in the two-storey frame for the artificial earthquake

The first irregularity cannot be accounted for by the proposed numerical model but it is able to cope with the second one. To evaluate its relevance in the response, Fig. 7 shows a comparison between the numerical values of the first floor displacement response determined with the proposed model by considering the actual unequal values of the sliding thresholds indicated in Table 3 and by taking the average of such forces.

Plots in Fig. 7 show a good agreement, indicating a rather negligible influence of the difference between the superior and inferior sliding thresholds (Fig. 6).

To assess the validity of the proposed model to simulate accurately the response, Fig. 8 shows the experimental and numerical values of the first floor displacement; the numerical value is obtained from the proposed model by considering the values of the sliding thresholds indicated in Table 3. 
Plots in Fig. 8 show that, in spite of the irregular shape of the loops shown by Fig. 6, the agreement between numerical and experimental results is satisfactory.

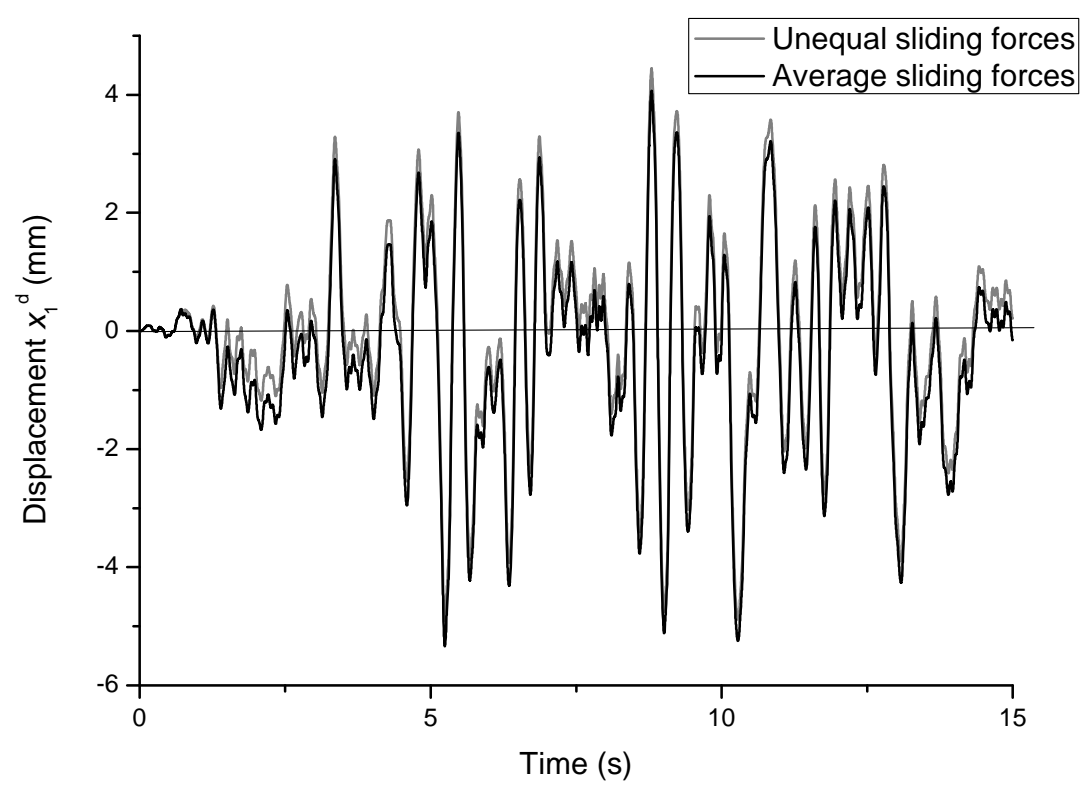

Fig. 7. Numerical time history responses of the two-storey frame for the artificial earthquake. First floor displacement

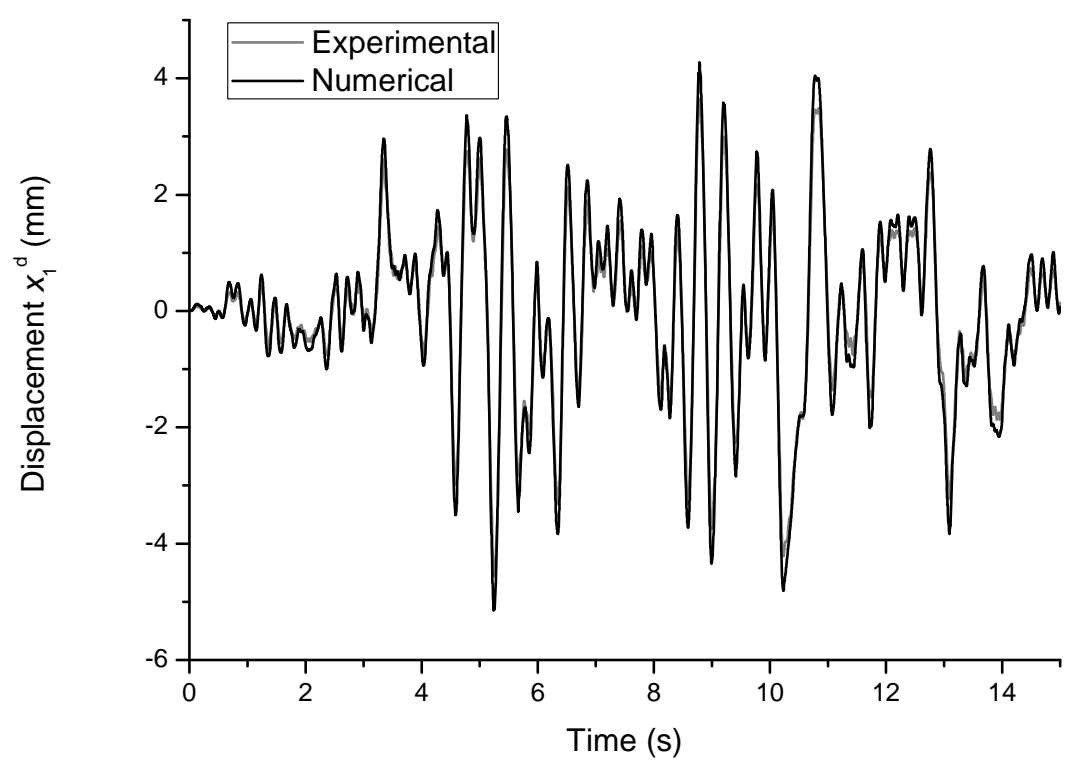

Fig. 8. Time history responses of the two-storey frame for the artificial earthquake. First floor displacement 


\section{Controversial issues}

\subsection{Introductory remarks}

This section presents some numerical and experimental results to contribute to clarify some of the aforementioned controversial issues about friction dissipators.

\subsection{Behavior for inputs containing pulses}

Fig. 9 displays the time history displacement responses of the single-story model for the Northridge Earthquake (Table 2). The bare, braced and protected frames are considered; the response of the protected frame is experimental while those of the bare and braced frames are simulated numerically with the proposed model.

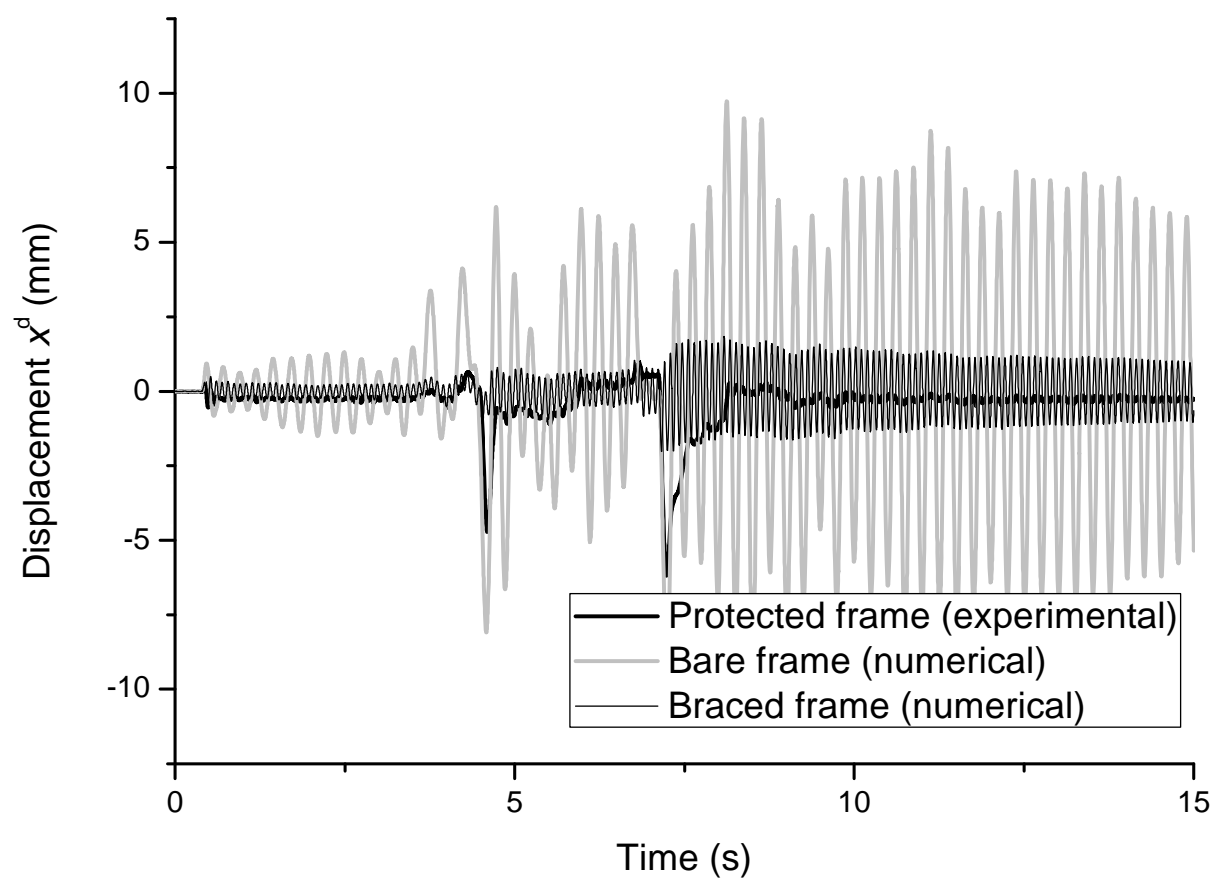

Fig. 9. Time history displacement responses of the single-story frame for the Northridge Earthquake

The comparison among the three plots in Fig. 9 shows that the response of the protected frame is significantly smaller than that of the bare frame; this tendency is also observed in the other analyzed cases (De la Cruz 2003). However, the balance between the protected and braced frames is unclear since the maximum response is larger for the protected frame while for the average value such trend is inverted. The protected frame response exhibits two peaks corresponding to the input pulses; hence, apparently, for strong crests the friction dissipators are not sufficiently efficient in reducing the maximum displacement. To help to understand why such peaks are not properly cut, the time history of the friction force $F$ is plotted in Fig. 10.

In Fig. 10 the sliding and sticking conditions can be clearly distinguished: sticking corresponds to friction forces smaller than $\mu N$ (see Fig. 2c) while sliding corresponds to $F= \pm \mu N$. At the onset of the input pulses ( $t=4.49 \mathrm{~s}$ and $t=7.13 \mathrm{~s}$ ) there is sticking and, hence, the response is not properly reduced; once the sliding is resumed ( $t=4.53 \mathrm{~s}$ and $t=7.15 \mathrm{~s}$ ), the peaks are immediately cut. To understand this better, it should be kept in mind that the behavior of the structure under sticking and sliding conditions is 
completely different: while sticking, the protected frame behaves like the braced one since there is no energy dissipation and only a stiffening effect is provided. Conversely, while sliding the frame behaves piece-wisely similarly to the bare frame, but with a decreased input since the friction force is constant and opposes motion (see equations 1 and 2).

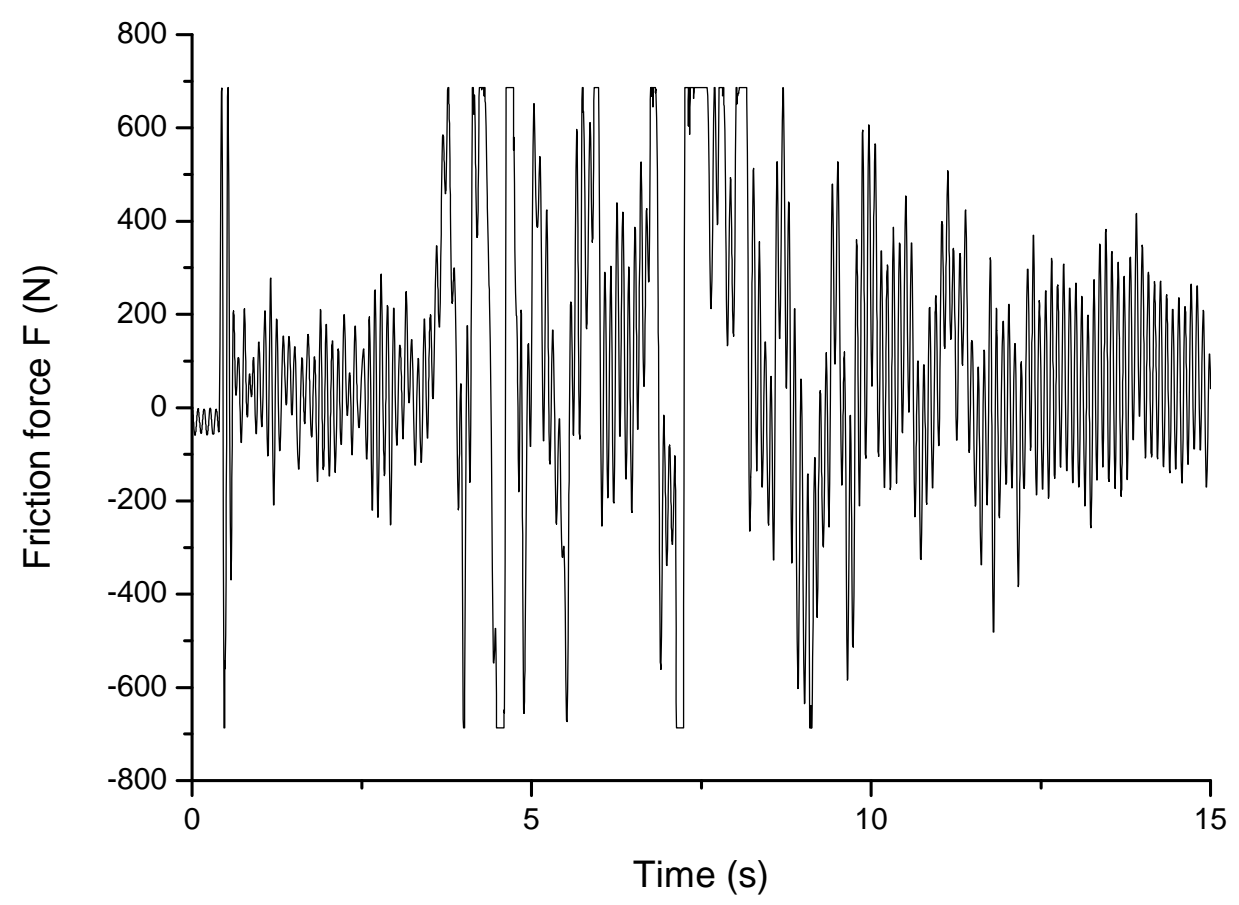

Fig. 10. Numerical time history of the friction force responses of the single-story frame for the Northridge Earthquake

About this issue, it can be concluded that for inputs containing pulses the friction dissipators are useful to reduce the response compared to the unbraced bare frame; regarding the comparison between dissipators and rigid braces (i.e. protected vs. braced frame), further research is needed.

\subsection{Capacity to cut resonance peaks}

The frequency of the sine dwell signal (4 Hz, as shown in Table 2) is close to the natural frequency of the single-story bare frame $(4.14 \mathrm{~Hz}$, as discussed previously). During sliding such frequency is not significantly changed since the friction force is essentially piecewise constant; it should be kept in mind that the sliding condition is frequent during intense inputs, as is this one. Therefore, in this case the protected frame behaves roughly like if its natural frequency were the one of the bare frame; hence, the motion can be considered near-resonance. Fig. 11 shows the time histories of the displacement responses of the single-story frame to the sine dwell signal. Two responses are plotted: protected frame (experimental results) and bare frame (simulated results). The input signal is also plotted in the top left corner.

Plots from Fig. 11 show that the friction dissipators are clearly able to cut the resonance peaks. It should be kept in mind that the damping factor of the bare frame is extremely low $\left(\xi_{1}=0.003141\right.$, as discussed previously) and therefore such resonance peaks are impressively high. It should be noted that, in friction devices installed in diagonal braces, the condition $\mu N>f_{0} \pi / 4$ is automatically fulfilled since the axial driving force in the device cannot exceed $\mu N$. 


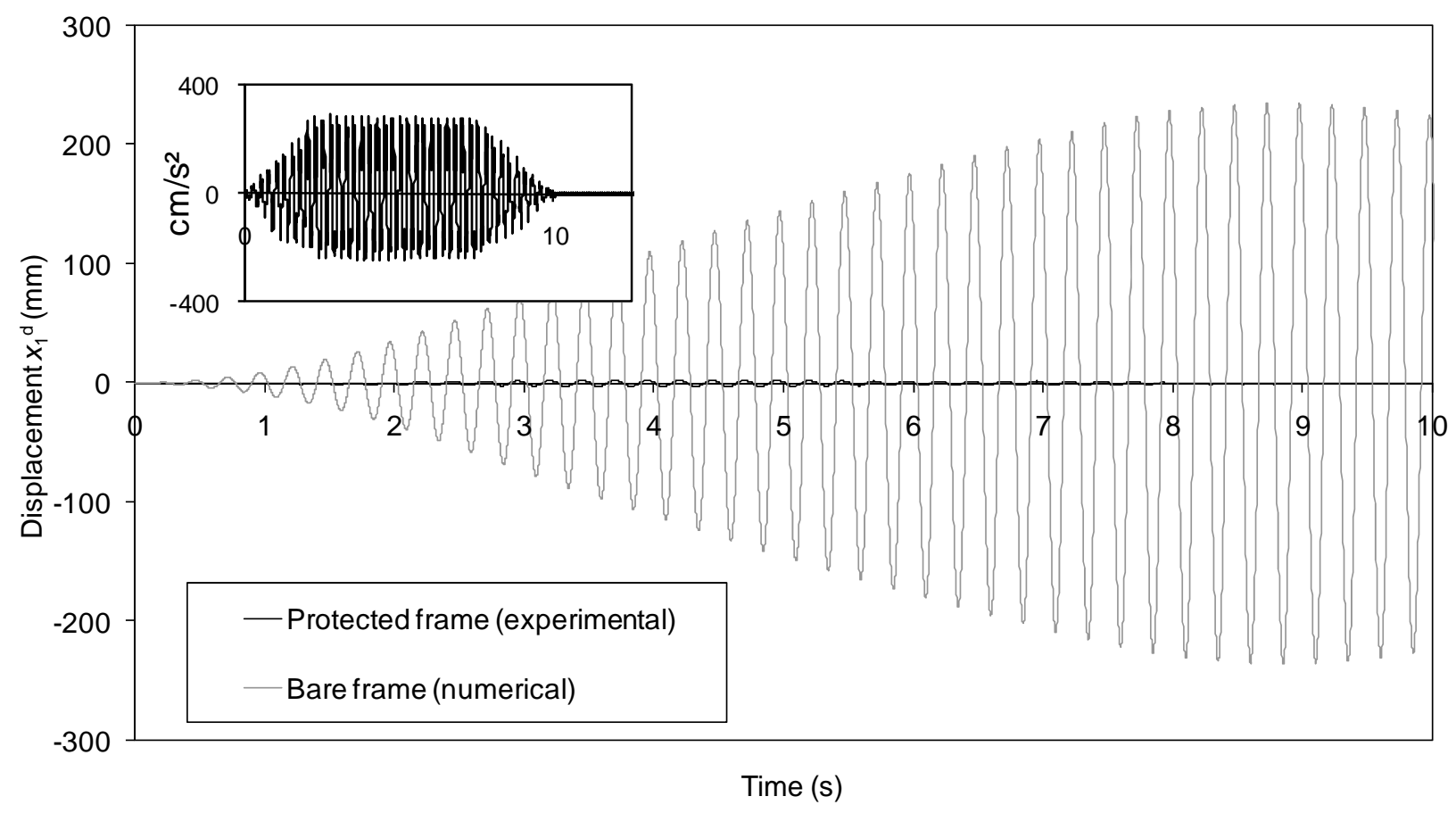

Fig. 11. Time history displacement responses of the single-story frame. Sine dwell input

\subsection{Introduction of high frequencies in the response}

The abrupt shift of the friction forces every time the sliding motion in the dissipators reverts might introduce high frequencies in the response, mainly in the acceleration. To try to clarify this issue, the experimental frequency contents of the input and of the response have been compared. Fig. 12 shows, for the two-storey building under the "Sine dwell 1" excitation (see Table 3), the magnitudes of the discrete Fourier transforms of the driving input acceleration and of the second floor acceleration response, respectively.
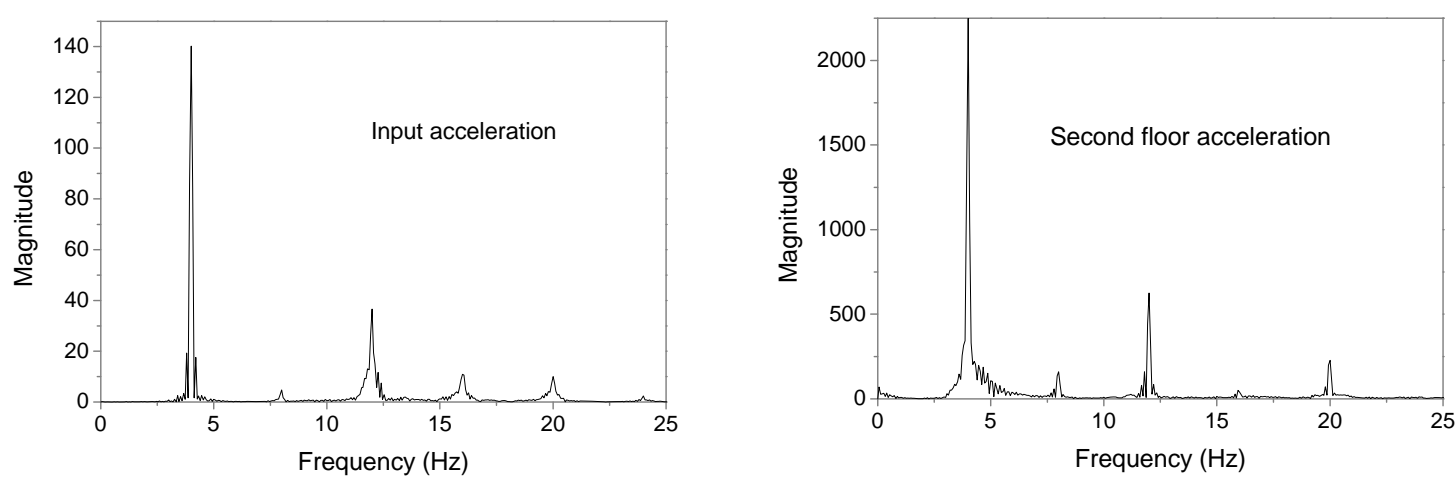

Fig. 12. Comparison between the Fourier transforms of input and output experimental accelerations of the two-storey frame. Sine dwell 1 input $(4 \mathrm{~Hz})$ 
The comparison between the two spectra in Fig. 12 shows that the same peaks can be observed in the input and in the output; it allows to conclude preliminarily that no additional frequencies have been introduced in the response. If similar analyses are performed in the other tests, equivalent results are obtained.

\subsection{Self-generated eccentricity}

The actual values of the sliding thresholds $\mu N$ are unpredictable, as well, onset and conclusion of sliding are highly random; hence, accidental differences between the dynamic behaviors of the front and rear frames (see Fig. 3 and Fig. 4) might arise. These self-generated eccentricities can generate twisting effects. To contribute to clarify this issue Fig. 13 shows the experimental time history response of the horizontal displacements of the single-story frame for the San Fernando Earthquake (Table 2).

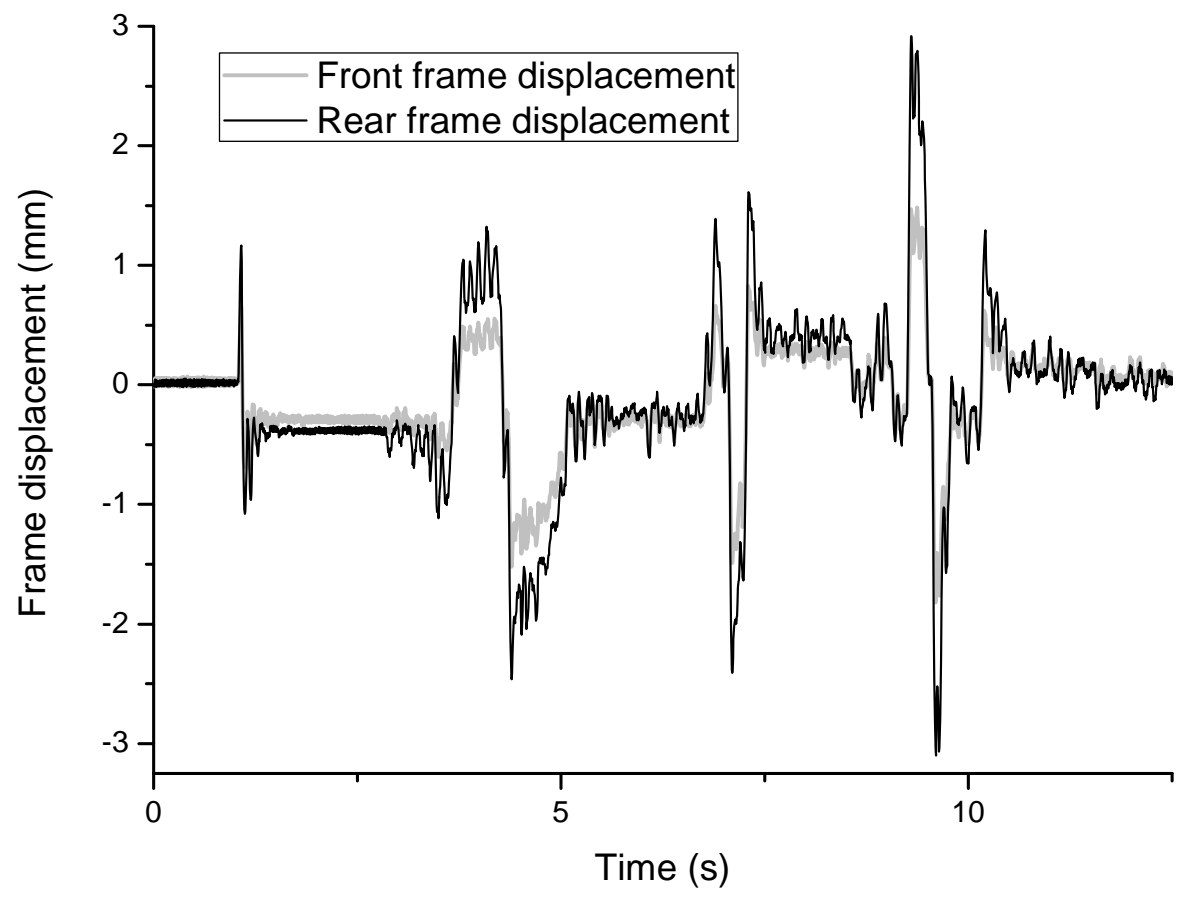

Fig. 13. Experimental horizontal displacements of the front and rear single-story frames. San Fernando Earthquake

Comparison between the plots from Fig. 13 shows that the differences among the peaks are relevant and that the offsets that can be observed in the instants between peaks are different for both frames. Therefore, self-generated torsional motion could not be neglected. Noticeably, the largest eccentricities correspond to instants where displacements are high and, hence, the dissipators are sliding. Similar conclusions can be derived in the other analyzed cases. However, this conclusion cannot be widely generalized since the torsional behavior largely depends on the ratio between torsional and translational stiffness of the structure.

\section{Conclusions}

This paper presents unidirectional shaking table tests carried out in the University of Bristol (UK) on two reduced-scale steel models of one and two-storey building structures incorporating a pair of parallel friction dissipators at each level. These experiments are simulated with an ad-hoc numerical model. The 
main conclusions arising from these experiments are summarized below.

- Experimental results to calibrate the numerical model. A wide set of experimental results useful to calibrate the proposed numerical model have been collected. The numerical and experimental results agree satisfactorily, even for irregularly shaped hysteresis loops.

- Behavior for inputs containing pulses. The considered dissipators are useful to reduce the response compared to the bare frame; regarding the braced frame the situation is unclear.

- Capacity to cut resonance peaks. These dissipators are able to cut the resonance peaks; even the sharper ones, corresponding to low damped structures.

- Introduction of high frequencies in the response. The comparison between the input and output spectra shows that their peaks correspond to the same frequencies. Hence, it can be preliminarily concluded that no additional frequencies have been introduced.

- Self generated eccentricity. The experiments show that significant induced twisting effects arise in most of the cases.

- Feasibility of simple friction dissipators. The considered devices are extremely simple and performed satisfactorily. However, the durability and the operation under saturation conditions have not been deeply investigated.

- Characterization of the hysteretic behavior. The hysteretic behavior of the considered devices has been roughly characterized. Two major irregularities of the hysteresis loops have been observed: non-flat sliding branches and differences among the superior and inferior sliding thresholds; the dependency on such facts is numerically investigated.

\section{Acknowledgements}

This work has received financial support from the Spanish Government under project CGL200800869/BTE.

\section{References}

Aiken, I.D. and Kelly, J.M. (1990), Earthquake Simulator Testing and Analytical Studies of Two EnergyAbsorbing Systems for Multistory Structures, Report UCB/EERC-90/03, University of California, Berkeley.

Aiken, I.D., Nims, D.K., Whittaker, A.S. and Kelly, J.M. (1993), “Testing of Passive Energy Dissipation Systems”, Earthquake Spectra, 9(3), 335-370.

Anagnostides, G. and Hargreaves, A.C. (1990), "Shake Table Testing on an Energy Absorption Device for Steel Braced Frames”, Soil Dynamics and Earthquake Engineering, 9(3), 120-140.

Bathe, K.J. (1982), Finite Element Procedures in Engineering Analysis, Prentice-Hall.

Cherry, S. and Filiatrault, A. (1993), "Seismic Response Control of Buildings Using Friction Dampers", Earthquake Spectra, 9(3), 447-466.

Cho, C.G. and Kwon, M. (2004), "Development and modeling of a frictional wall damper and its applications in reinforced concrete frame structures”, Earthquake Engineering and Structural Dynamics, 33(7), 821838.

Chopra, A.K. (2001), Dynamics of Structures. Theory and Applications to Earthquake Engineering, PrenticeHall.

Colajanni, P. and Papia, M. (1997), "Hysteretic characterization of friction-damped braced frames", Journal of Structural Engineering, ASCE, 123(8), 1020-1028.

De la Cruz, S.T., López-Almansa, F. and Oller, S.H. (2001), "Numerical Simulation of the Dynamic Behavior of Building Structures Equipped with Friction Energy Dissipators", $2^{\text {nd }}$ European Conference on Computational Mechanics, Krakow, Poland.

De la Cruz, S.T., López-Almansa, F., Bozzo, L. and Pujades, L. (2002), "Parametric study of the efficiency of frictional dampers to protect the buildings from earthquake loads", Proceedings of the $12^{\text {th }}$ European Conference on Earthquake Engineering, London, UK.

De la Cruz, S.T. (2003), Contribution to the assessment of the efficiency of friction dissipators for seismic protection of buildings, Doctoral Dissertation, Technical University of Catalonia, Barcelona.

De la Cruz, S.T., López-Almansa, F. and Oller, S.H. (2007), "Numerical Simulation of the Dynamic Behavior 
of Building Structures Equipped with Friction Energy Dissipators”, Computers \& Structures, 85(1-2), 3042.

De la Llera, J.C., Almazán, J.L. and Vial I.J. (2005), “Torsional balance of plan-asymmetric structures with frictional dampers: analytical results”, Earthquake Engineering and Structural Dynamics, 34(9), 10891108.

Den Hartog, J.P. (1985), Mechanical Vibrations, Dover.

Dimova, S., Meskouris, K. and Kratzig, W.B. (1995), "Numerical Technique for Dynamic Analysis of Structures with Friction Devices”, Earthquake Engineering and Structural Dynamics, 24(6), 881-898.

Dimova, S. and Hirata, K. (2000), "Simplified seismic fragility analysis of structures with two types of friction devices”, Earthquake Engineering and Structural Dynamics, 29(6), 1153-1175.

Filiatrault, A. and Cherry, S. (1987), "Performance Evaluation of Friction Damped Braced Steel Frames under Simulated Earthquake Loads”, Earthquake Spectra, 3(1), 57-78.

Fitzgerald, T.F., Anagnos, T., Goodson, M. and Zsutty, T. (1989), “Slotted Bolted Connections in Aseismic Design for Concentrically Braced Connections”, Earthquake Spectra, 5(2), 383-391.

Foti, D., Bozzo, L. and López-Almansa, F. (1998), "Numerical Efficiency assessment of energy dissipators for seismic protection of buildings”, Earthquake Engineering and Structural Dynamics, 27(6), 543-556.

Frau, C.D. and Saragoni, G.R. (2005), "Demanda sísmica de fuente cercana. Situación del oeste argentino”, Congreso Chileno de Sismología e Ingeniería Antisísmica. IX Jornadas. Concepción, Chile.

Grigorian, C.E., Yang, T.S. and Popov, E.P. (1993), "Slotted Bolted Connection Energy Dissipators", Earthquake Spectra, 9(3), 491-504.

Hanson, R., Aiken, I., Nims, D., Richter, P. and Bachmann, R. (1993), "State of the art of the practice in seismic energy dissipation”, Proceedings of the ATC 17-1 on Seismic Isolation, Energy Dissipation and Active Control, San Francisco.

Housner, G.W., Bergman, L.A., Caughey, T.K., Chassiakos, A.G., Claus, R.O., Masri, S.F., Skelton, R.E., Soong, T.T., Spencer, B.F. and Yao, J.T.P. (1997), "Structural control: past, present and future”, ASCE Journal of Engineering Mechanics, 123(9), 897-971.

Iyama, J., Seo, C.Y., Ricles, J.M. and Sause, R. (2009), "Self-centering MRFs with bottom flange friction devices under earthquake loading”, Journal of Constructional Steel Research, 65(2), 314-325.

Levy, R., Marianchik, E., Rutenberg, A. and Segal, F. (2000), "Seismic design methodology for friction damped braced frames”, Earthquake Engineering and Structural Dynamics, 29(11), 1569-1585.

Levy, R., Lavan, O. and Rutenberg, A. (2005), "Seismic Design of Friction-Damped Braced Frames Based on Historical Records”, Earthquake Spectra, 21(3), 761-778.

Lu, L.Y., Chung, L.L., Wuc, L.Y. and Lin, G.L. (2006), "Dynamic analysis of structures with friction devices using discrete-time state-space formulation”, Computers \& Structures, 84(15-16), 1049-1071.

Moreschi, L.M. and Singh, M.P. (2003), "Design of yielding metallic and friction dampers for optimal seismic performance”, Earthquake Engineering and Structural Dynamics, 32(8), 1291-1311.

Morgen, B.G. and Kurama, Y.C. (2004), “A Friction Damper for Post-Tensioned Precast Concrete Beam-toColumn Joints”, PCI Journal, 49(4), 112-133.

Morgen, B.G. and Kurama, Y.C. (2009), "Characterization of two friction interfaces for use in seismic damper applications”, Materials and Structures, 42(1), 35-49.

Newmark, N.M., Blume, J.A. and Kapur K.K. (1973), “Seismic Design Spectra for Nuclear Power Plants”, ASCE Journal of the Power Division, 99(2), 287-303.

Nims, D.K., Richter, P.J. and Bachman, R.E. (1993), “The Use of the Energy Dissipating Restraint for Seismic Hazard Mitigation”, Earthquake Spectra, 9(3), 467-490.

Ng, C.L. and Xu, Y.L. (2006), "Seismic response control of a building complex utilizing passive friction damper: Experimental investigation”, Earthquake Engineering and Structural Dynamics, 35(6), 657-677.

Pall, A.S and Marsh, C. (1982), "Response of friction damped braced frames”, Journal of Structural Division, ASCE, 108(6), 1313-1323.

Pall, A.S. (1989), "Friction damped connections for precast concrete cladding”, Proceedings of the International symposium on architectural precast concrete cladding, Chicago.

Pall, A.S., Vezina, S., Proulx, P. and Pall, R. (1993), "Friction-Dampers for Seismic Control of Canadian Space Agency Headquarters”, Earthquake Spectra, 9(3), 547-557.

Palsson, H., Goodno, B., Craig, J. and Will, K. (1984), "Cladding influence on dynamic response of tall buildings”, Earthquake Engineering and Structural Dynamics, 12(2), 215-228.

Rao, R., Gergely, P. and White, R.N. (1996), “A Simplified Design Method for Retrofit of Gravity Load Design RC Frames with Friction Dampers”, Proceedings 11 WCEE, Acapulco, Mexico. 
Richter, P.J., Nims, D.K., Kelly, J.M. and Kallembach, R.M. (1990), “The EDR-Energy Dissipating Restraint. A New Device for Mitigation of Seismic Effects”, Proceedings of the 1990 SEAOC Convention, Tahoe, Nevada.

Ricles, J.M., Sause, R., Wolski, M., Seo, C.Y. and Iyama J. (2006), "Post-tensioned moment connections with a bottom flange friction device for seismic resistant self-centering steel MRFs”, $4^{\text {th }}$ International conference on earthquake engineering, Taipei, Taiwan.

Soong, T.T. and Dargush, G.F. (1997), “Passive energy dissipation systems in structural engineering”, John Wiley.

Sumitomo Metals Industries Ltd., (1987), Friction dampers for earthquake response control, Report 12.

Tena, A. (2007), "State of the Art and State of the Practice for Energy Dissipation and Seismic Isolation of Structures in Mexico and Other Latin American Countries", $10^{\text {th }}$ World Conference on Seismic Isolation, Energy Dissipation and Active Vibration Control of Structures, Istanbul, Turkey.

Tsai, K.C., Chou, C.C., Lin, C.L., Chen, P.C. and Jhang, S.J. (2008), "Seismic self-centering steel beam-tocolumn moment connections using bolted friction devices”, Earthquake Engineering and Structural Dynamics, 37(4), 627-645.

Tyler, R. (1985), “Test on a Brake Lining Damper for Structures”, Bulletin of the New Zealand National Society for Earthquake Engineering, 18(3), 280-284.

Vezina, S., Proulx, P., Pall, R. and Pall, A. (1992), "Friction-Dampers for Aseismic Design of Canadian Space Agency”, $10^{\text {th }}$ World Conference on Earthquake Engineering, Madrid.

Vial, I.J., De la Llera, J.C., Almazán, J.L. and Ceballos, V. (2006), “Torsional balance of plan-asymmetric structures with frictional dampers: experimental results”, Earthquake Engineering and Structural Dynamics, 35(15), 1875-1898.

Way, D. (1996), “Friction-damped moment resisting frames”, Earthquake Spectra, 12(3), 623-633.

Whittaker, A.S., Bertero, V.V., Thompson, C.L. and Alonso, L.J. (1991), "Seismic Testing of Steel Plate Energy Dissipation Devices”, Earthquake Spectra, 7(4), 563-604.

Wu, B. and Ou, J. (2003), "The pseudo-viscous frictional energy dissipator: a new device for mitigating seismic effects”, Earthquake Engineering and Structural Dynamics, 32(1), 31-48.

Yang, T.S. and Popov, E.P. (1995), "Experimental and Analytical Studies of Steel Connections and Energy Dissipators", Earthquake Engineering Research Center, University of California, Berkeley.

Zhu, S., Zhang, Y. and Lu, L.W. (2006), "Seismic Analysis of Steel Framed Buildings with Self-Centering Friction Damping Braces”, 4th International conference on earthquake engineering, Taipei, Taiwan.

Zhou, F.L., Xian, Q.L., Tan, P., Cui, J. and Huan, X.Y. (2007), “Current Status of Application, R\&D and Design Rules for Seismic Isolation, Energy Dissipation and Structural Control of Buildings, Bridges and Viaducts and Cultural Heritage in the P. R. China”, $10^{\text {th }}$ World Conference on Seismic Isolation, Energy Dissipation and Active Vibration Control of Structures, Istanbul, Turkey. 